\title{
O Impacto da Produção Científica das Ciências Administrativas no Desenvolvimento Local
}

\author{
Raphaela Reis Silva ${ }^{1 *}$ \\ Universidade Federal de Santa Catarina (UFSC), Florianopolis - SC, Brasil \\ Luis Moretto Neto', \\ Universidade Federal de Santa Catarina (UFSC), Florianopolis - SC, Brasil \\ Giovanna Fonseca Demonti, \\ Universidade Federal de Santa Catarina (UFSC), Florianopolis - SC, Brasil
}

\section{Angela Serafim Godinho Espindula}

Universidade Federal de Santa Catarina (UFSC), Florianopolis - SC, Brasil

\section{Recebido em 1 de Julho de 2016. Aceito em 3 de Setembro de 2016 \\ RESUMO}

Este artigo pretende investigar o alinhamento entre a produção científica das ciências administrativas com o desenvolvimento local. Usou-se o método qualitativo pelo meio da análise das respostas dos questionários enviados, por correio eletrônico, aos líderes de grupos de pesquisas cadastrados e certificados pelo Conselho Nacional de Desenvolvimento Científico e Tecnológico (CNPQ). O objetivo deste trabalho é identificar a convergência entre a pauta de investigações científicas dos professores credenciados no programa de pósgraduação em Administração (PPGA) da Universidade Federal de Santa Catarina (UFSC) com o desenvolvimento local. Contudo, seu desfecho traz uma série de questões que necessitam de reflexões mais profícuas e norteadoras.

Palavras-chave: produção científica; desenvolvimento local; ciências administrativas. ABSTRACT

This article intends to investigate the alignment of the scientific production of administrative sciences to local development. He used the qualitative method by analyzing the responses from questionnaires sent by e-mail, the leaders of research groups registered and certified by the National Scientific and Technological Development Council (CNPq). The objective of this study is to identify the convergence between the agenda of scientific research of teachers in accredited postgraduate program in Management (PPGA) of the Federal University of Santa Catarina (UFSC) with local development. However, its outcome has a number of issues that need more fruitful and guiding thoughts.

Keywords: scientific production; local development; administrative sciences.

\section{Introdução}

Quando refletimos sobre o modelo centro-periferia no que se refere à disposição global, vemos que o Brasil se encontra na posição de periferia, ou seja, um país dependente dos países centrais. Assim, questionamos: como mudar essa posição? Adentramos a questão abandonando essa dicotomia e passamos a nos questionar sobre como nos tornaremos um país autônomo, que busca atender às necessidades particulares de sua população.

$\mathrm{Na}$ nossa concepção, isso é possível por meio da educação, pela aquisição de conhecimento. Defendemos que o papel da educação vai além de preparar o trabalhador para suas atividades

\footnotetext{
* Autor para correspondências. Raphaela Reis Silva

e-mail: castroreis@gmail.com
} 
profissionais, ele visa a emancipação dos indivíduos. Dando a ele condições de refletir sobre sua existência e sua vida.

A importância das ações que venham a ser feitas em ciência e tecnologia para o desenvolvimento brasileiro é hoje evidente. Contudo, o conhecimento como posto atualmente também não é capaz de nos possibilitar tal mudança. O conhecimento é gerador de ciência, e esta materializa-se através de tecnologias que almejam o desenvolvimento humano. Esse cenário seria o ideal. Percebemos que na atualidade, as tecnologias privilegiam o desenvolvimento das forças produtivas que reificam o sistema capitalismo, reproduzindo a dominação e exploração (GOULART; CARVALHO, 2008). Ademais, nossas pesquisas estão conectadas com os sistemas científicos das grandes potências, resultando na ausência de criação de knowhow, apenas o importando.

As raízes da disfunção das universidades advêm, dentre outras, de nossa condição periférica; devido à nossa pauta de consumo imitativa e à industrialização via substituição de importações num contexto onde os países centrais já haviam se industrializado. Dagnino e Filho (2011) ressaltam que a maioria dos trabalhos que tratam da temática universidadesociedade, na realidade se debruçam sobre a relação da universidade com as empresas privadas intermediada pelo propósito de transferência de conhecimento. Assim, "naturalizando" a ideia de que o foco das universidades públicas deve estar sob a empresa.

Como se não existissem no cenário econômico-produtivo outros agentes além da empresa privada. "A imensa maioria dos professores e pesquisadores segue o seu rumo "cientificista", enquanto que alguns poucos procuram encarar uma "nova" forma de fazer ciência, ensino e extensão, cada um dos três se retroalimentando". (DAGNINO; FILHO, p.39).

Entretanto, no âmbito das universidades e da produção de conhecimento, existem grupos e pesquisadores, comprometidos com a transformação dos contextos sociais de referência, que tem procurado avançar no sentido da aproximação às demandas populares. Isso posto, o nosso foco de análise será as universidades, sendo estas o lócus de produção científica e tecnológica. Na tentativa de investigar como se apropriar do potencial desse lugar numa outra direção.

Nesse sentido, o objetivo desse trabalho é identificar a convergência entre a pauta de investigações científicas dos professores credenciados no programa de pós-graduação em Administração (PPGA) da Universidade Federal de Santa Catarina (UFSC) com o desenvolvimento local.

O artigo está, então, organizado em três partes, além da presente introdução: na próxima seção será apresentado os fundamentos teóricos composto pelas reflexões a cerca do ensino da Administração, da produção científica e algumas teorias sobre desenvolvimento. E por fim, este é concluído com algumas questões para futuras pesquisas, que decorreram das colocações das seções que a precederam.

\section{Referencial teórico}

\subsection{O ensino em Administração no Brasil}

O crescimento dos Estados Unidos no século XX, consolidando-se como superpotência, influenciou fortemente o desenvolvimento da área de administração. De acordo com Alcadipani e Bertero (2014), é possível elencar três instituições que tiveram um papel de destaque na exportação desse produto, chamado management, para o Brasil nas décadas de 50 e 60. A primeira instituição é a missão diplomática dos Estados Unidos no Brasil, na qual envia ajuda financeira para a Escola de Administração de Empresas de São Paulo (EASP), para Universidade Federal do Rio do Sul (UFRGS) e para Universidade Federal da Bahia (UFBA).

O Institute of Inter-American Affairs e a Michigan State College of Agriculture and Applied Sciences (MSU) executam também um papel fundamental, com um contrato entre as duas instituições para que haja um

O Impacto da Produção Científica das Ciências Administrativas no Desenvolvimento Local -

Raphaela Reis Silva, Luis Moretto Neto, Giovanna Fonseca Demonti e Angela Serafim Godinho Espíndula 
apoio à Fundação Getúlio Vargas na condução de uma escola de negócios no Brasil. O objetivo do Institute of Inter-American Affairs é melhorar a imagem dos Estados Unidos na América Latina em um contexto de pré II Guerra Mundial e a MSU tinha o ideal norte-americano de levar o "progresso" ao mundo, através da implantação de uma escola de negócios no Brasil que deveria servir de centro difusor no país (ALCADIPANI; BERTERO, 2014). A imagem do profissional administrador de empresas estava associada à imagem de modernidade, da mudança e do alinhamento do país com as nações que se modernizavam (BERTERO, 2006).

E por último a Fundação Ford criada por Henry Ford I, para fugir do pagamento de taxa sobre sua herança, financiou junto com o Conselho Nacional de Desenvolvimento Cientifico e Tecnológico (CNPQ) atividades relacionadas com a expansão do management no Brasil.

O ensino de administração apresenta muitas peculiaridades, dado a receptividade histórica de sua inserção como ciência (SILVA, 2014). E sua evolução no Brasil se deu marcadamente em termos de história e regulamentação da profissão, segundo Lemos e Bazzo (2011), por quatro principais momentos. O primeiro, após a década de 1940, marca o surgimento e reconhecimento da profissão de administrador, assim, o ensino de administração segue o processo de desenvolvimento do país, expandindo-se a partir das demandas de profissionalização dos quadros de pessoal das grandes unidades produtivas. Consequentemente tal expansão favoreceu a regulamentação da profissão. Posteriormente, a criação da Resolução número 2 de 4 de outubro de 1993 do Conselho Federal de Educação que fixa os mínimos de conteúdos e duração do curso de graduação em administração, foram estabelecidas a carga horária e as matérias de formação básica e instrumental, formação profissional, disciplinas eletivas e complementares e ainda o estágio supervisionado. O terceiro momento é circunscrito pela criação de um conjunto de ações e experiências em avaliação do ensino, com o objetivo de melhorar a qualidade da educação, com início a partir da metade da década de 90. E por fim, a institucionalização das Diretrizes Curriculares Nacionais do curso de Graduação em Administração em 2004, onde tais diretrizes permitem a flexibilidade, a contextualização e a interdisciplinaridade dos conteúdos ministrados, ao invés da aplicação de currículos.

Das transformações que marcaram nosso país durante o século passado, merecem destaque a urbanização e o crescimento da classe média urbana. Essa mudança no quadro populacional brasileiro gerou uma demanda pelo serviço de educação, que foi atendido precariamente, especialmente a de terceiro grau, motivo pelo qual o ensino privado dominou o país, sendo um privilégio de poucos terem acesso.

Coadunando com as ideias de Bertero (2006), Lemos e Bazzo (2011) afirmam que a graduação em administração sofreu uma intensa massificação, dados disponibilizados pelo Instituto Nacional de Estudos e Pesquisas Educacionais Anísio Teixeira (INEP), por meio do Censo da Educação Superior de 2009 dão conta de que o curso de administração é o curso com maior número de matrículas (1.102.579) no ensino superior no Brasil, considerando as modalidades: presencial (874.076) e à distância (228.503), o que corresponde a 18,5\% do total de matrículas. De acordo com o Conselho Federal de Administração, os cursos de administração, pedagogia, direito e engenharia são responsáveis por quase metade das matrículas do ensino superior do país, mostram os dados do Censo da Educação Superior de 2009, divulgado pelo Ministério da Educação (MEC).

A atratividade pelo curso se deu maioria pela classe média e média/baixa e, a graduação deste curso no Brasil é bem diferente daquela observada em outros países e o que se entende por "carreira de administrador" também, transformando-se num curso de "graduação geral". Para Bertero (2006), em geral, as graduações de administração estão formando executores ao invés de executivos, e maioria dos formados não executarão atividades de administradores, como decidir estratégias e controlar o processo produtivo.

Lemos e Bazzo (2011) defendem a necessidade de renovação na estrutura curricular dos conteúdos, de forma a colocar a ciência e a tecnologia em novas concepções vinculadas ao contexto social. Objetivando, não somente a promoção do progresso técnico, mas particularmente o desenvolvimento humano, identificando em que medida o ensino da administração pode estar coerente com tal visão, de maneira a formar profissionais conscientes de seu papel na sociedade. 


\subsection{Produção Científica}

Essa seção tem por objetivo esclarecer o que entendemos por produção científica e sua finalidade. Além disso, pretende-se verificar como se caracteriza a produção científica das ciências administrativas no Brasil.

A ciência, presente entre os gregos desde a Idade Antiga, busca formas racionais de conhecer a natureza. A universidade foi criada na Idade Média com o objetivo de formar pensadores e administradores da Igreja. De acordo com Goulart (2005), a conexão entre ciência e universidade se deu nos últimos dois séculos, sendo um dos frutos do Iluminismo. Tal aproximação, que se deu gradualmente, levou a consagração da universidade como espaço por excelência para ciência e, posteriormente, com a tecnologia.

No início, as preocupações científicas estavam centradas na contemplação, sem preocupação de intervenção, norteada predominantemente pela lógica, como ilustra a Física, de Aristóteles. A passagem da ciência antiga para a ciência moderna impactou o modo de entender o trabalho cientifico, e aí se destacam as argumentações dos filósofos Francis Bacon (1979) com noções do empirismo, René Descartes (1979) do racionalismo e Immanuel Kant contribui com o criticismo (KEINERT, 2011). Assim, as bases fornecidas pela ciência moderna contribuíram no desenvolvimento histórico do método científico.

A Europa, berço da ciência moderna, já contava com universidades desde o século X, vinculadas a interesses e orientações religiosas. Goulart (2010) cita a Escola de Medicina de Salerno, na Itália, como o princípio da universidade, seguida da de Bolonha, em 1088, especializada em Direito, e posteriormente a Universidade de Paris, criada na segunda metade do século XII.

Goulart (2005) salienta que a pesquisa científica, no século XVII, se encontrava em segundo plano e era desenvolvida por intermédio do trabalho individual de pesquisadores que criavam as Sociedades ou Academias de Ciências como ponto de encontro e debates. Até final do século XVIII, as chamadas universidades tradicionais funcionavam como centros transmissores de um conhecimento estabelecido. Somente a partir do século XIX, a ciência, como atividade geradora de conhecimento passa a se desenvolver no âmbito das universidades europeias. O marco da universidade moderna foi a criação da Universidade de Berlim em 1810, cujas bases se assentam na busca da verdade, na formação profissional e na cultura geral, constituindo-se como centro de investigação e pesquisa, e não somente como centro de reprodução de conhecimento.

Essa incorporação da ciência pelas universidades tradicionais, portadora de princípios da pesquisa e do trabalho científico desinteressado, consolidou-se com uma instituição acadêmica. Esse modelo fora adotado por diversos países como Inglaterra, Holanda e Estados Unidos (GOULART, 2010). Nos demais países do mundo, inclusive no Brasil, o início da produção científica não se vincula às universidades. A ciência por aqui é inaugurada como prática de escolas isoladas, como na Escola de Minas de Ouro Preto em 1876; de alguns pesquisadores e institutos isolados, como Adolfo Lutz, em São Paulo, desde 1883; e o Instituto Manguinhos, no Rio de Janeiro, em 1901 (GOULART, 2005).

Embora houvessem discussões e propostas de mudanças sobre a ciência e a educação brasileiras desde 1920, somente em 1931 é formulada a primeira legislação federal delineando as características específicas de uma organização universitária. Resultado de amplo debate entre as diversas correntes de pensamento, duas em especial merecem destaque: uma delas é o grupo identificado como "pioneiros da educação nova", da qual participavam Anísio Teixeira e Fernando de Azevedo, entre outros educadores. A segunda corrente, formada por um grupo de intelectuais católicos, liderados por Alceu Amoroso Lima.

Goulart (2005) salienta que o arcabouço legal criado concedia ao Ministério da Educação e Saúde Pública e ao Conselho Nacional de Educação prerrogativas de interferências como a aprovação dos regulamentos internos, taxas acadêmicas, etc. Quanto à pesquisa, alegava que o povo brasileiro não possuía a maturidade cultural e a necessidade de resultados imediatos. Assim, o foco estava na formação de professores e para formação profissional.

O Impacto da Produção Científica das Ciências Administrativas no Desenvolvimento Local Raphaela Reis Silva, Luis Moretto Neto, Giovanna Fonseca Demonti e Angela Serafim Godinho Espíndula 
Foi somente em 1934, com a criação da Universidade de São Paulo (USP), que o Brasil possuía uma universidade efetivamente multifuncional. Iniciou-se pela Faculdade de Filosofia, Ciências e Letras, constituída por professores estrangeiros e equipes dedicadas à pesquisa. Assim, a criação da USP foi considerada um marco da inserção da pesquisa como uma das principais atribuições das universidades do Brasil. Esse modelo se disseminou, gradualmente, para os demais Estados brasileiros e foi impulsionado após a Segunda Guerra Mundial, com o ideário de construir o desenvolvimento econômico e social, no qual a ciência é um elemento estratégico (GOULART, 2005).

No Brasil, essa condição se traduz na criação de algumas instituições como Centro Tecnológico da Aeronáutica (CTA), Instituto Militar de Engenharia (IME) e do Instituto Tecnológico da Aeronáutica (ITA). Ademais, em 1951 foi criado o Conselho Nacional de Pesquisas, atual CNPq e da Campanha Nacional de Aperfeiçoamento do Ensino Superior, hojeCAPES (GOULART, 2005).

Os anos de 1950 revelam-se ricos em possibilidades investigativas, posto que oferece um repertório considerável de ideias, propostas e instituições que tomaram o tema educação como crucial ao futuro do país. Os intelectuais da educação - como Anísio Teixeira, Fernando de Azevedo, Florestan Fernandes, Antonio Candido - naquela época operavam em duas frentes do saber: na primeira, retomavam estudos que privilegiavam as dimensões singulares da cultura brasileira e, com isso, delineavam um novo perfil para as ciências sociais; e na segunda, empenhavam-se na articulação de projetos junto com o Estado (FREITAS, 2002). Havia ainda outras tradições sociológicas que também reivindicavam novas interpretações para a ideia de conhecimento local como as ideias advindas de Guerreiro Ramos.

Em decorrência da realidade específica do país, havia uma perspectiva que defendia que a pesquisa científica poderia colaborar na qualificação do debate sobre o desenvolvimento do país. Conforme Freitas (2002), esse movimento se iniciou nos anos 20 até o final dos anos 50. Ressalta ainda que a partir dos anos de 1960, o papel da pesquisa tornou-se um objeto de diferenciação entre os intelectuais que buscavam a edificação de uma ciência social para o país.

A produção científica busca por soluções de problemas humanos universais, levandose em consideração que o conhecimento produzido é fruto de experiências criativas de pertinência sócio-cultural (GOULART; CARVALHO, 2008). A construção da ciência decorre de dois fatores essenciais: o contexto histórico de sua elaboração, que incluem aspectos sociais, econômicos e políticos; e os atores, que constroem, criticam e ainda se beneficiam do saber (LEMOS e BAZZO, 2011). Nesse sentido, a natureza do conhecimento se caracteriza como produto sempre inacabado, construído, recriado por atores cujas relações ocorrem no mundo das ideias.

Ademais, as discussões sobre os problemas locais já vinham de antes, desde o século XIX e do período que precedeu e acompanhou a Revolução de 1930 (FREITAS, 2002). De fato, nos anos de 1950, a busca pelo caráter regional ou local de determinados problemas ganhou novo sentido e amplitude. Isso se deve a força dos intelectuais daquele momento que além de reabrir alguns debates, inaugurava novas perspectivas.

A discussão acerca da afirmação da brasilidade e se esta dar-se-ia incorporando ou rejeitando a cultura estrangeira, iniciou-se nos anos 10 e só foi interrompida nos anos 60 com o golpe de Estado. Freitas (2002) salienta que esse debate, para além desse marco cronológico, é uma das "questões do século". Esses debates instigaram além dos sociológicos, o movimento artístico, a história, a ciência política (FREITAS, 2002). Deve-se acrescentar ainda o impacto da nova ciência econômica advinda da CEPAL (Comissão Econômica para a América Latina e o Caribe) a partir de 1948, com as contribuições de Raul Prebisch e Celso Furtado, entre outros.

No Brasil, a produção científica concentra-se nas universidades públicas, o que as coloca no centro de políticas nacionais de ciência e tecnologia. Assim, o papel que as instituições de ensino superior (IES) exercem no campo científico é de suma importância, pois além de definir sua estrutura de funcionamento, mapear hierarquias, delinear poderes e influenciar a adoção de estratégias de ação e estas promovem a legitimação e divulgação dos saberes (LEMOS e BAZZO, 2011). Vinculada primordialmente à pósgraduação, a produção de conhecimento científico e sua publicização representam quesito determinante na avaliação de cursos e de pesquisadores. A internacionalização dessa produção é determinada como um dos itens mais valorizados em várias áreas do conhecimento por meio da publicação de artigos em periódicos 
internacionais, celebração de convênios com instituições de ensino estrangeiras e a publicação de periódicos nacionais em língua inglesa.

Contudo, a ciência está alienada devido a determinação social dos objetivos de sua própria atividade pois se submete aos ditames materiais e objetivos de produção do órgão reificado de controle, ou seja, do capital. Os ditames são oriundos daqueles que acumularam capitais por séculos, esclarecidos no modelo (na relação) centro-periferia do sistema-mundo. Países desenvolvidos têm-se preocupado em alcançar e deter a liderança e a hegemonia do conhecimento científico em diferentes áreas. Portanto, há uma dominação dos países centrais no campo científico e por consequência, a legitimidade ali construída corresponde a seus interesses, seus valores, sua visão de mundo e do mundos dos outros.

Nesse sentido, Ramos (1996) e Furtado (1980) propuseram a necessidade imperiosa de apropriarmos criativamente teorias e conceitos universais a partir de uma reflexão serena e corajosa sobre a cultura brasileira. Segundo Freitas (2002), a redução sociológica de Ramos trazia para o âmbito das ciências sociais a argumentação cepalina sobre a "substituição de importações" como etapa necessária ao desenvolvimento do país. Há uma recomendação da UNESCO de que a solução dos problemas educacionais brasileiros passaria necessariamente pela análise científica das reais condições sociais e culturais do país (FREITAS, 2002).

Nas ciências administrativas, a expansão global da academia e do conhecimento intensificou a hegemonia anglo-americana, ao fortalecer uma tendência de integração e pretensa universalização, inibidora de uma produção local que a desafie. É preciso redefinir o valor do conhecimento científico como bem comum. De escrever para temáticas que interessam ao centro e nos distanciamos da nossa realidade e perdemos a pertinência sóciocultural. O campo científico dispõe de autonomia, que interfere diretamente no estado da relação de forças nas lutas entre os detentores de poder (BOURDIEU, 1986).

Portanto, o que pretendemos é identificar a existência de possíveis pesquisas científicas que não visem ampliar ou fortalecer os conhecimentos inscritos em uma lógica instrumental de cálculo dos meios com relação aos fins ou que melhorem o desempenho econômico das organizações. Mas, que almejem tentativas de emancipar as pessoas dos mecanismos de opressão tendo, de fato, o humano como ponto fundamental.

\subsection{Desenvolvimento local}

Esse terceiro tópico do referencial teórico se propõe a delimitar o conceito de desenvolvimento local e suas principais correntes, além de buscar ferramentas de mensurá-lo tendo em vista as necessidades da realidade brasileira.

Nesse sentido, verifica-se que a partir do ano de 1940, o debate teórico sobre o conceito de desenvolvimento, toma notoriedade devido aos impactos devastadores do grande conflito da Segunda Guerra Mundial e a necessidade dos países centrais de garantirem o próprio crescimento enfrentando o desafio de dirimir as contradições em termos de concentração de riqueza e paralela exclusão social. De acordo com Sachs (2000) na Conferência das Nações Unidas sobre o Ambiente Humano, em Estolcomo, uma das pautas foi o aproveitamento racional da natureza em favor das populações locais, ou seja, um ecodesenvolvimento.

O tema "desenvolvimento" dos países atrasados ou distribuição desigual da riqueza entre as nações volta a ser central nas discussões político-econômica mundial. Fiori (1999) destaca que o retorno dessas discussões se deve ao reconhecimento da gravidade da crise que se alastrou a partir do Leste Asiático e da impotência das políticas de lidarem com efeitos de tal crise em 1999.

A discussão que se põe é a questão da distribuição desigual da riqueza entre as nações e possíveis caminhos de desenvolvimento das nações. Desde o início do século XIX, a concentração de poder político e

O Impacto da Produção Científica das Ciências Administrativas no Desenvolvimento Local Raphaela Reis Silva, Luis Moretto Neto, Giovanna Fonseca Demonti e Angela Serafim Godinho Espíndula 
de riqueza capitalista está nas mãos de um reduzido número de Estado. As nações periféricas enfrentam o poderio das grandes potencias econômicas e se sujeitam a essa tirania econômica. Para que se atinja o desenvolvimento, a nação precisa ter objetivo e interesse estratégicos de longo prazo.

Poucos países superaram o atraso em relação a Inglaterra, como a Alemanha, os Estados Unidos e o Japão e algumas colônias do Canadá e da Austrália. O restante do mundo permanece dominado sob a especialização e exportações de produtos primários. Chang (2002) na obra "Chutando a Escada: A Estratégia do Desenvolvimento em Perspectiva Histórica" defende a tese que as políticas e instituições tão recomendadas aos países em crescimento não foram adotadas pelos desenvolvidos quando se achavam nesse processo. Se tivessem adotadas as políticas que agora recomendam as nações em desenvolvimento não seriam o que são hoje. As recomendações hodiernas são: políticas macroeconômicas restritivas; liberalização do comércio internacional; livre circulação dos investimentos; processo de privatização e; desregulamentação econômica.

Ao contrário disso, os países desenvolvidos - Grã-Bretanha, Estados Unidos, Alemanha, França e Japão - usaram ativamente políticas industrial, comercial e tecnológica com características intervencionistas para promover a indústria nascente durante o período de catch-up . Essas políticas previam, a saber, proteção tarifária por meio dos impostos de importação; financiamento de investimento para a tecnologia e para a educação; programas de investimento público voltados para a infra-estrutura; formação de parcerias público-privada e; impedimento de transferência de tecnologia por meio das patentes.

Por meio de uma análise comparativa dos casos específicos da Dinamarca e países asiáticos e da América Latina, Carneiro (2006) destaca que as políticas econômicas de inspiração liberal adotadas por estes não contribuíram no sentido de estabelecer um novo padrão de desenvolvimento. Ao contrário do que aconteceu com a Dinamarca e países asiáticos que adotaram políticas intervencionistas, tiveram maior êxito em termos de desenvolvimento. O desenvolvimento nos países da América Latina necessita, antes de tudo, de uma modificação nas relações Estado-mercado, com a ampliação da ação do primeiro para enfrentar as fragilidades dessas economias tais como inconversibilidade monetária, atraso tecnológico e heterogeneidade social (CARNEIRO, 2006).

Nessa direção, Furtado (1992) aponta que mesmo que a industrialização tenha contribuído para o aumento da produtividade nos países subdesenvolvidos, não é condição suficiente para o desenvolvimento social. Atualmente, economistas discutem sobre as teorias de desenvolvimento coerentes com mundo atual e com o processo histórico que o capitalismo já percorreu. As visões mais restritas sobre a temática identificam-no como o crescimento do Produto Nacional Bruto (PNB), aumento das rendas pessoais, industrialização, avanço tecnológico ou modernização social. Além disso, pode ser visto também como um processo de expansão das liberdades reais que as pessoas desfrutam.

A concepção do desenvolvimento, típica do século passado, um processo exógeno, importado de fora para dentro por meio de poderosas injeções de capital, tecnologia, know how e infraestruturas operadas pelo poder central, traz sinais de inadequação. Indicando a necessidade de abordagens orientadas pela busca da indução de processos endógenos que valorizem e aproveitem as características do território.

Para Sen (2000), adicionada a essa visão mais restrita, o desenvolvimento depende também de outros determinantes como as disposições sociais e econômicas e os direitos civis. O economista indiano destaca o papel dos mercados no processo de desenvolvimento, por sua vez, importante componente das liberdades básicas relacionadas aos mecanismos de troca e transação. "A liberdade de participar do intercâmbio econômico tem um papel básico na vida social” (SEN, 2000, p. 22). O autor justifica-se por fazer tal consideração, no intuito de examinar as privações que algumas comunidades permanecem excluídas dos benefícios da sociedade orientada para o mercado, e também de criticar o mecanismo de mercado.

A privação de liberdade econômica, na forma de pobreza extrema, pode tornar a pessoa uma presa indefesa na violação de outros tipos de liberdade. (...) A privação de liberdade econômica pode gerar a privação de liberdade social, assim como a privação de liberdade social ou política pode, da mesma forma, gerar a privação de liberdade econômica (SEN, 2000, p. 23). 
A tese defendida por Sen (2000) é de um processo de desenvolvimento integrando considerações econômicas, sociais e políticas. Uma abordagem que permite a apreciação simultânea no processo de desenvolvimento de papéis vitais como de muitas instituições diferentes incluindo mercados e organizacionais relacionadas ao mercado, governos e autoridades locais, partidos políticos e outras instituições cívicas, sistema educacional e oportunidades de diálogo e debate abertos. Essa abordagem permite ainda reconhecer o papel dos valores sociais e costumes que podem influenciar as liberdades que as pessoas desfrutam. Portanto, o foco não teve estar somente ao valor dos mercados, mas também apreciar o papel de outras liberdades para além das econômicas, como as sociais e políticas que melhoram a vida que as pessoas podem levar.

\section{Metodologia}

Este trabalho foi desenvolvido sob a forma de uma pesquisa qualitativa, que envolve a aplicação de questionários semi-estruturados com nove (9) líderes dos grupos de pesquisas vinculados a Universidade Federal de Santa Catarina e ao coordenador do Programa de Pósgraduação em Administração. Os questionários foram adaptados do material de coleta de dados da tese de doutorado de Goulart (2005). Além dos questionários, os pesquisadores acessaram informações sobre os grupos de pesquisas disponíveis.

Inicialmente, acessou-se o sitio eletrônico do Programa de Pós-graduação em Administração da Universidade Federal de Santa Catarina e no link "Núcleos de Pesquisas", coletamos os grupos de pesquisas e seus respectivos endereços eletrônico - totalizando 14 grupos, a saber:

- $\quad$ Centro Universitário de Estudos e Pesquisas sobre Desastres (CEPED);

- $\quad$ Centro de Estudos em Microfinanças (GVcemf);

- $\quad$ Instituto de Pesquisas e Estudos em Administração Universitária (INPEAU);

- Laboratório de Estudos da Multifuncionalidade Agrícola e do Território (LEMATE);

- $\quad$ Núcleo de Estudos de Economia Catarinense (NECAT);

- $\quad$ Núcleo de Estudos em Estratégia, Gestão e Sustentabilidade (NEEGES);

- $\quad$ Núcleo de Estudos Organizacionais Críticos e Transdisciplinares (NEOCT);

- $\quad$ Núcleo de Inteligência Competitiva Organizacional em Marketing e Logística (NICO);

- Núcleo Interdisciplinar de Estudos em Planejamento e Gestão Estratégicos (NIEPGE);

- $\quad$ Núcleo Interdisciplinar de Estudos em Gestão de Produção e Custos (NIEPC);

- $\quad$ Núcleo de Estudos sobre Organizações e Delimitação (NUSOL);

- Observatório da Realidade Organizacional;

- Observatório da Sustentabilidade e Governança; e

- $\quad$ Organizações, Racionalidade e Desenvolvimento (ORD)

A seguir, acessamos o Diretório dos Grupos de Pesquisa no Brasil para buscar informações de cada um dos grupos de pesquisa certificados levantados na etapa anterior. Assim, dos 14 grupos informados no sítio da Instituição apenas 10 (dez) estão cadastrados e certificados pelo Conselho Nacional de Desenvolvimento Científico e Tecnológico (CNPQ), agência do Ministério da Ciência, Tecnologia e Inovação (MCTI). Contudo, um deles é coordenado por professores de uma instituição superior de ensino (IES) fora do Estado de Santa Catarina, portanto fora excluído dessa pesquisa.

O Impacto da Produção Científica das Ciências Administrativas no Desenvolvimento Local Raphaela Reis Silva, Luis Moretto Neto, Giovanna Fonseca Demonti e Angela Serafim Godinho Espíndula 
Os questionários foram enviados repetidas vezes por correio eletrônico para os 9 (nove) líderes de pesquisas da referida Instituição, porém tivemos apenas 2 (dois) questionários devolvidos: do coordenador do Programa de Pós-graduação em Administração e de um líder de um dos grupos de pesquisa. MouraPaula e Ferraz (2015) afirmam que o silêncio organizacional revela que a ausência do relato está sendo usado como instrumento de luta.

Para analisar os materiais coletados, optou-se pela adoção da abordagem de Análise de Conteúdo, desenvolvida por Bardin (1986), que prevê três etapas de execução: a) análise prévia, que consiste na organização do material, operacionalização e sistematização, escolha dos documentos, formulação de hipóteses, objetivos e elaboração de indicadores e leitura; b) análise exploratória, que consiste em codificações e classificações, caracterizando-se por ser uma fase longa e exigindo o trabalho de uma equipe, na qual seus membros atuam como juízes do trabalho de codificação e classificação temática; c) tratamento de resultados obtidos e interpretação, que consiste na tabulação e aplicação de técnicas descritivas de análises.

\section{Análise de dados}

Sistematizamos as informações obtidas no sítio eletrônico e perguntas via correio eletrônico que fizemos ao coordenador do Programa de Pós-graduação em Administração e aos líderes dos núcleos de pesquisa. Infelizmente, com apenas dois questionários respondidos nossa análise não será capaz de mapear a convergência entre a pauta de investigações científicas dos professores credenciados no programa de pósgraduação em Administração (PPGA) da Universidade Federal de Santa Catarina (UFSC) com o desenvolvimento local. Por outro lado, nos instigou ainda mais em compreender esse espaço - as universidades - responsável pela produção de conhecimentos. No contexto brasileiro, a produção que se concentra nas universidades públicas, o que as coloca no centro de políticas nacionais de ciência e tecnologia.

Os respondentes apresentaram que os programas de pós-graduação ou as instituições de formação e pesquisa que se constituem em referência de qualidade acadêmico-científica, na área de Administração, no Brasil, são apontados por terem uma estrutura de apoio adequada como biblioteca, laboratórios e recursos financeiros. Sendo este, um dos principais obstáculos enfrentados pelo Programa em estudo: falta de estrutura de apoio da Universidade Federal de Santa Catarina.

Ademais, indicaram também a Fundação Getúlio Vargas (EAESP e EBAPE) como referência de tradição em pesquisa. Instituição pioneira nos estudos sobre as ciências administrativas, que visitaram diversos cursos de Administração Pública localizadas em universidades norte-americanas, para assim elaborar os programas de ensino de Administração no Brasil. A ciência da administração que temos na atualidade decorre de dois fatores essenciais: o contexto histórico de sua elaboração, que incluem aspectos sociais, econômicos e políticos; e os atores, que constroem, criticam e ainda se beneficiam do saber (LEMOS e BAZZO, 2011). Nesse sentido, esse processo se deu com o apoio de duas instituições: o Institute of InterAmerican Affairs e a Michigan State College of Agriculture and Applied Sciences (MSU). Como apontando anteriormente, o objetivo do Institute of Inter-American Affairs é melhorar a imagem dos Estados Unidos na América Latina em um contexto de pré II Guerra Mundial e a MSU tinha o ideal norte-americano de levar o "progresso" ao mundo, através da implantação de uma escola de negócios no Brasil que deveria servir de centro difusor no país (ALCADIPANI; BERTERO, 2014).

Sobre as finalidades das pesquisas realizadas, a primeira delas é atender as demandas da sociedade civil e das organizações públicas e em seguida auxiliar a formulação de políticas públicas no setor. Coadunando, com o objetivo apresentado no sítio do núcleo de pesquisa "empreender estudos interdisciplinares sobre a relação entre os processos organizacionais e o desenvolvimento territorial sustentável, na perspectiva da ecossocioeconomia e abrangendo a ação coletiva empreendida pelas organizações da sociedade civil, organizações públicas e privadas”.

Contudo, não indicaram quais são as formas de relacionamento que o grupo estabelece com a sociedade. Mesmo sendo essas as prioridades do grupo, eles alegaram não estabelecer "estratégias" para identificar parceiros. As pesquisas realizadas são decorrentes da participação de chamadas de editais ou de 
convites decorrentes da expertise do grupo em alguns campos de atividades e de conhecimento. Sobre as principais ações que o grupo de pesquisa desenvolve para elevar sua qualidade acadêmico-científica, não se considera o atendimento as necessidades da sociedade civil, mas sim a perpetuação do grupo na comunidade científica, e os recursos financeiros são fundamentais nesse processo.

O líder do grupo apontou a elaboração de dois projetos voltados para a elaboração de metodologias de avaliação para um órgão do governo e também para uma entidade nãogovernamental. Entretanto, não indicou os mecanismos de avaliação de resultados e os principais resultados alcançados nessas parceiras e muito menos a criação de conselhos, comitês ou outras formas organizacionais para implementação das ações em parcerias. Assim, não foi possível identificar a posição ou papel do grupo nestas composições e seus impactos na sociedade civil.

O coordenador do Programa apontou expectativas em modificar e melhorar a sociedade, ao destacar que docentes do Centro Sócio-Econômico assumem cargos no governo e em organizações sem fins lucrativos em posições estratégicas. Além desse fator, destacou a existência de projetos de extensão voltados às mais diversas demandas da comunidade. É essa ação nos chama atenção, pois pode estar aí uma novidade capaz de traçar nossas perspectivas para as universidades brasileiras. Novaes (2012), na obra Reatando um Fio Interrompido, investiga a atuação dos professores-extensionistas como uma forma para se pensar a "universidade necessária". Ao observar o estabelecimento de laços simbólicos e práticos de pesquisa e extensão com os trabalhadores precarizados, informais, que veem no cooperativismo e associativismo uma resposta para seus problemas. Esse movimento, destaca Novaes (2012) representa uma pequena ruptura na ideia "naturalizada" de que o o foco das universidades públicas deve estar sob a empresa. Como se não existessem no cenário econômico-produtivo outros agentes além da empresa privada.

\section{Desfecho e indagações}

Diante desse cenário, muitas limitações e reflexões surgem. A primeira limitação é a impossibilidade de identificar a convergência entre a pauta de investigações científicas dos professores credenciados no programa de pós-graduação em Administração (PPGA) da Universidade Federal de Santa Catarina (UFSC) com o desenvolvimento local. Assim, o objetivo desse trabalho, consideramos que não fora alcançado. Por outro lado, gerou questões que pretendemos aprofundar em novas pesquisas: Por que pesquisadores tem dificuldade em participar de pesquisas? Por que optaram pelo silêncio? Quais os motivos que os levaram a permanecerem no silêncio? Autopreservação? Carga de trabalho? Quais são as consequências desse silêncio para eles e para as pesquisas? A carga de trabalho dos professorespesquisadores é excessiva ou alienante?

Outras questões visam ampliar a temática central desse trabalho também surgiram: por que uma parcela muito seleta da universidade pública brasileira tem se interessado pela reflexão e realização de pesquisas junto a sociedade? Será que há grupos que estão conseguindo estabelecer laços mais estreitos com a sociedade? Qual é o sentido desses laços? O que estão trazendo de novidade para o debate do ensino, da pesquisa e da extensão? O que estão trazendo para o debate sobre a relação da universidade pública com a sociedade, especialmente no campo da Administração?

Ademais, e os professores-extensionistas? No âmbito das universidades e da produção de conhecimento, existem grupos e pesquisadores, comprometidos com a transformação dos contextos sociais de referência, que tem procurado avançar no sentido da aproximação às demandas populares por meio de iniciativas de extensão. As atividades de extensão são um conjunto de ações dirigidas à sociedade, vinculadas aos aprendizados adquiridos ao decorrer do curso. Em outros termos, atividades que possam ser voltadas à uma modificação da sociedade, juntamente com uma possibilidade, por parte do aluno, de externalizar de maneira prática os conhecimentos adquiridos em sala de aula, fora da mesma. Ao mesmo tempo podem, ou não, acabarem por adquirir conhecimentos novos, através de estudos mais aprofundados em assuntos pontuais e eventuais conversas com professores mais dotados de conhecimento nas mesmas.

O Impacto da Produção Científica das Ciências Administrativas no Desenvolvimento Local Raphaela Reis Silva, Luis Moretto Neto, Giovanna Fonseca Demonti e Angela Serafim Godinho Espíndula 
Objetivando, não somente a promoção do progresso técnico, mas particularmente o desenvolvimento humano.Talvez seja essa a saída para os professores que querem ir além, que querem se desvencilhar das teias compostas de normas e regras institucionalizadas, que os impedem de irem além do produtivismo.

Essas respostas demandam a realização de reflexões e de pesquisas que estão além do que se propõe neste trabalho e que serão perseguidas.

\section{REFERÊNCIAS BIBLIOGRÁFICAS}

ALCADIPANI, R., BERTERO, C. O. (2014).Os EUA e a exportação e a expansão do ensino de Management no Brasil nas décadas de 1950 e 1960. Trabalho apresentado ao IV Colóquio Internacional de Epistemologia e Sociologia da Ciência da Administração, Florianópolis.

SILVA, R. R. C. C. (2014). Os desafios das diretrizes curriculares para o curso de graduação em Administração oferecido por um consórcio. Trabalho apresentado no XI Congresso Brasileiro de Ensino Superior a Distância. Florianópolis.

BACON, F. Novum organum. 2 ed. São Paulo: Abril Cultural, 1979.

BARDIN, L. (1986)L'Analyse de contenu. Paris: Presses Universitaires de France.

BERTERO, C. O. (2006). Ensino e Pesquisa em Administração. São Paulo: Thomson.

BOURDIEU, Pierre. (1996). As regras da arte: gênese e estrutura do campo literário. São Paulo: Companhia das Letras.

CARNEIRO, R.O. O desenvolvimento revisitado. São Paulo em Perspectiva, v. 20, n. 3, pg. 73-82, jul/ago 2006.

CHANG, HA-JOON.Chutando a Escada - A Estratégia do Desenvolvimento em Perspectiva Histórica. Unesp, 2002.

DESCARTES, R. Discurso do Método, inRené Descartes, coleção os pensadores.São Paulo: Abril Cultural, 1979.

FIORI, J. L. Introdução: de volta a questão da riqueza de algumas nações. In: FIORI, J. L. (org.) Estado e moedas no desenvolvimento das nações. RJ: Ed. Vozes, 2a. edição, 1999, p. 11 - 48.

FREITAS, M.C. de. (2002). A pesquisa educacional como questão intelectual na história da educação brasileira (breves anotações para uma hipótese de trabalho). In.: FREITAS, M.C. de; KULMANN, JR. M. (orgs.) Os intelectuais na história da infância. São Paulo: Corteza.

FURTADO, C. (1992).Subdesenvolvimento revisitado. Revista Economia e Sociedade. Campinas, n. 1 ago, p. 5 - 19.

FURTADO, C. (1980). Pequena introdução ao desenvolvimento: enfoque interdisciplinar. SP: Editora Nacional.

GIANNELLA, V., CALLOU, A. E. P. (2011). A emergência do paradigma de desenvolvimento centrado no território na observação de duas políticas no Cariri cearense. Cadernos EBAPE.BR., 3(9), p. 803-827.

GOULART, S. (2005). Sobre a interferência da produção científica e tecnologia da universidade no desenvolvimento local: o caso da Ciência da Computação. (Tese de doutorado). Universidade Federal de Pernambuco, Recife, Brasil.

GOULART, S., CARVALHO, C. A. (2008) O caráter da internacionalização da produção científica e sua acessibilidade restrita. RAC. 12(3), p. 835-853. Históricos do curso de Administração no Brasil, CFA. Disponível em: <http://www2.cfa.org.br/agencia-de-noticias/cfanews/administracao-e-curso-maisprocuradono-ensino-superior-mostra censo $>$. Acessado em 16 de abril de 11.

IPIRANGA, A. S. R.; QUEIROZ, W. V.; FROTA, G. dos S. L.; CÂMARA, S. F.; ALMEIDA, P. C. da H. (2012)Estratégias de inovação de catching-up: as ligações de aprendizagem entre um instituto de P\&D e pequenas empresas.RAP. Rio de Janeiro, 43(6), p. 677-700.

LEMOS, D. da C., BAZZO, W. (2011) A. Administração como ciência social aplicada: integrando ciência, tecnologia e sociedade no ensino de administração. Pensamento Contemporâneo em Administração. 5(3), p. 1-14.

KEINERT, M. C. Kant: o apóstolo da razão pura e da crítica sistemática. In: Razão, sonho e sensibilidade. 2 ed. São Paulo: Editora Duetto, 2011, p. 7-13.

MOURA-PAULA, M. J. de, FERRAZ, D. L. da S. (2015). Silêncio organizacional: introdução e crítica. Cadernos EBAPE.BR. Rio de Janeiro, 13(3), p. 516-529.

NICOLINI, Alexandre. "Qual será o futuro da fábrica de administradores?" In: ANPAD, 25, 2001, Campinas. Anais. Campinas: ANPAD, 2001. 
NOVAES, H. T.(2012). Reatando um fio interrompido: a relação universidade-movimentos sociais na América Latina. São Paulo: Editora Expressão Popular. 335 p.

RAMOS, G. (1996). A Redução sociológica. 3 ed. Rio de Janeiro: Editora UFRJ.

SACHS, I. (2000) Caminhos para o desenvolvimento sustentável. Rio de Janeiro, Garamond.

SEN, A. (2000). Desenvolvimento como liberdade. São Paulo, Companhia das Letras. 